\title{
Safety and Effectiveness of Reza Band in Management of Laryngopharyngeal Reflux Disease: A Preliminary Study
}

\author{
Jonghyun Lim, Byung Joon Yoo, Dong Won Lee, Chang Myeon Song, Yong Bae Ji, and Kyung Tae \\ Department of Otorhinolaryngology-Head and Neck Surgery, Hanyang University College of Medicine, Seoul, Korea
}

\author{
임종현 · 유병준 · 이동원 · 송창면 · 지용배 · 태 경 \\ 한양대학교 의과대학 이비인후-두경부외과학교실
}

인후두 역류증 환자에서 Reza Band 사용의 안전성 및 효과: 예비연구

\author{
Received January 3, 2018 \\ Revised February 19, 2018 \\ Accepted March 9, 2018 \\ Address for correspondence \\ Kyung Tae, MD, PhD \\ Department of Otorhinolaryngology- \\ Head and Neck Surgery, \\ Hanyang University \\ College of Medicine, \\ 222 Wangsimni-ro, Seongdong-gu, \\ Seoul 04763, Korea \\ Tel $+82-2-2290-8585$ \\ Fax $+82-2-2293-3335$ \\ E-mail kytae@hanyang.ac.kr
}

Background and Objectives The main treatment of laryngopharyngeal reflux disease (LPRD) includes life style modification and proton pump inhibitor (PPI) medication. However, LPRD is sometimes refractory to PPI medication. The Reza band has been developed to exert external pressure on the upper esophageal sphincter thus preventing gastric acid reflux to the larynx and pharynx. The aim of this study was to evaluate safety and efficacy of using the Reza band in patients with LPRD.

Subjects and Methods We prospectively enrolled 16 LPRD patients who were refractory to PPI medication and who had agreed to wear the Reza band. Patients were treated with the Reza band and PPI medication simultaneously or only the Reza band. We studied complications related to the Reza band, analyzed Reflux Symptom Index (RSI) and Reflux Finding Score (RFS) before and after the application of the band up to 12 weeks.

Results The Reza band was endured by 15 patients except one patient. One patient $(6.25 \%)$ ceased wearing the band due to pain and discomfort in the neck. No major complications occurred, except one patient who reported mild neck discomfort when the band was applied. The mean value of RSI before the application of the Reza band was $12.31 \pm 6.43$, which significantly improved at 8 weeks and 12 weeks $(9.17 \pm 5.08, p=0.005$ and $8.20 \pm 5.59, p=0.007$, respectively) post-treatment. The mean value of RFS before the application of the Reza band was $13.50 \pm 2.97$, which significantly improved at $2,4,8$, and 12 weeks $(p<0.05)$ post-treatment. Conclusion We conclude that the Reza band is safe and effective for the treatment of LPRD in properly selected patients. Korean J Otorhinolaryngol-Head Neck Surg 2018;61(8):421-5

Key Words Laryngopharyngeal reflux · Proton pump inhibitor · Reza band · Safety · Upper esophageal sphincter.

\author{
서 론 \\ 인후두 역류 질환(laryngopharyngeal reflux disease, LPRD) \\ 은 하부식도 괄약근의 기능 저하로 위의 내용물이 인후두로 \\ This is an Open Access article distributed under the terms of the Creative Commons \\ Attribution Non-Commercial License (https://creativecommons.org/licenses/by-nc/4.0) \\ which permits unrestricted non-commercial use, distribution, and reproduction in any \\ medium, provided the original work is properly cited.
}

\begin{abstract}
역류하거나, 역류한 위산이 식도에 머무르는 시간이 길어지거 나, 위식도 역류가 인후두로 넘어오는 것을 막아주는 상부식 도 괄약근의 부전으로 인해 발생할 수 있다. ${ }^{1-4)}$ 인후두 역류 질환의 치료는 식생활 개선 등의 생활 습관 개선과 함께 약물 치료로써 제산제, $\mathrm{H} 2$ 수용체 차단제, 위장관 운동 촉진제, 양 성자 펌프 억제제(proton pump inhibitor, PPI) 등을 사용하 는 것이 효과적이다. ${ }^{5,6)}$
\end{abstract}


그러나 생활 습관 개선 및 약물에 대한 치료를 장기간 시 행함에도 불구하고 효과가 제한적인 환자에서 최근 상부식 도 괄약근의 부전을 개선시키는 방법이 시도되고 있는데, 그 중 Reza band(Somna Therapeutics, Germantown, WI, USA) 는 상부식도 괄약근의 보조 장치로서 상부식도의 압력을 증 가시켜 인후두 역류 질환을 치료하기 위해 고안된 장치이다. Reza band로 치료하였을 때 인후두 역류증이 개선되었다는 몇몇의 보고가 해외에서는 있으나, ${ }^{7,8)}$ 한국에서는 아직 Reza band의 치료 경험이 없다. 이에 저자들은 본 연구에서 한국인 인후두 역류 질환 환자에서 Reza band 사용 경험을 토대로 안전성 및 효과를 확인하고자 하였다.

\section{대상 및 방법}

본 연구에서는 인후두 역류 증상으로 양성자 펌프 억제제 치료를 최소 6 개월 이상 지속함에도 불구하고 인후두 역류 증상이 지속되는 환자 중 Reza band 치료 연구에 동의한 16 명의 인후두 역류 질환 의심 환자를 대상으로 하였으며, 2017 년 1월부터 전향적으로 연구를 시행되었다. 본 연구는 한양대 학교병원 임상시험 심사위원회(Institutional Review Board) 의 승인을 받았으며 저자들과 Reza band와는 상충되는 이 해관계가 없었다(IRB No. HYUH 2017-03-004-003).

Reza band는 윤상 연골 부위 피부 위에 착용하여 상부식도 괄약근 위에 압력을 가하는 장치이다. 윤상 연골 부위 피부 에 닿는 부위는 쿠션으로 이루어져 있어 피부 자극을 줄이 고 외부 프레임이 쿠션이 지속적인 압력을 가할 수 있도록 받쳐준다. 또 자석으로 되어 있는 클랩이 있어 착용이 용이

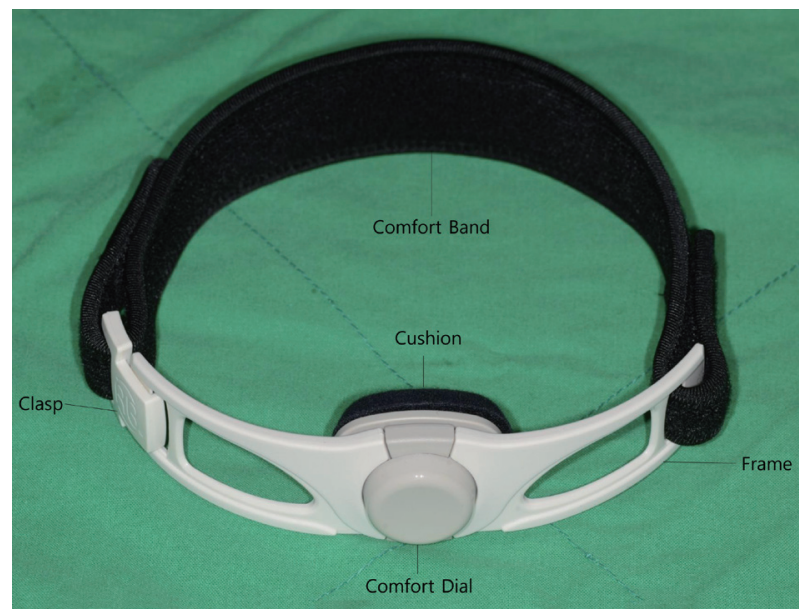

Fig. 1. The Reza band: The device for compression of the upper esophageal spincter. The cushion is designed to fit the cricoid area, and the frame keeps the cushion in place to provide consistent pressure. The magnet-assisted clasp allows wearing and removing the Reza band. The comfort dial of the Reza band allows patients to adjust for personal comfort.
하도록 설계되어 있으며, 가운데 있는 조절 장치로 개인이 압 력을 조절할 수 있다(Fig. 1). 외래에서 Reza band 착용 및 사 용에 대한 교육을 시행하였는데, Reza band가 윤상 연골 부 위 위를 누를 수 있도록 착용하게 하였으며(Fig. 2), 압력은 대개 $20 \mathrm{~mm} \mathrm{Hg}$ 이상으로 시작하여 압력 조절 장치로 착용 시 큰 불편함이 없는 압력으로 자가 조절하라 하였다(Fig. 3). 주로 수면 시에 착용하도록 하였으나 환자가 가능하면 낮 에 활동 중에도 착용하도록 권고하였다.

감염성 인두염이나 후두염이 있거나, 임산부 또는 모유 수 유 중인 경우, 폐쇄성 무호흡이 동반된 경우, 갑상선 또는 후 두 종양이 있는 경우 및 기타 연구에 영향을 미칠 수 있는 기 왕력을 지닌 환자는 연구에서 제외하였다.

본 연구에서 목표 치료 기간 및 추적 관찰 기간은 12 주로

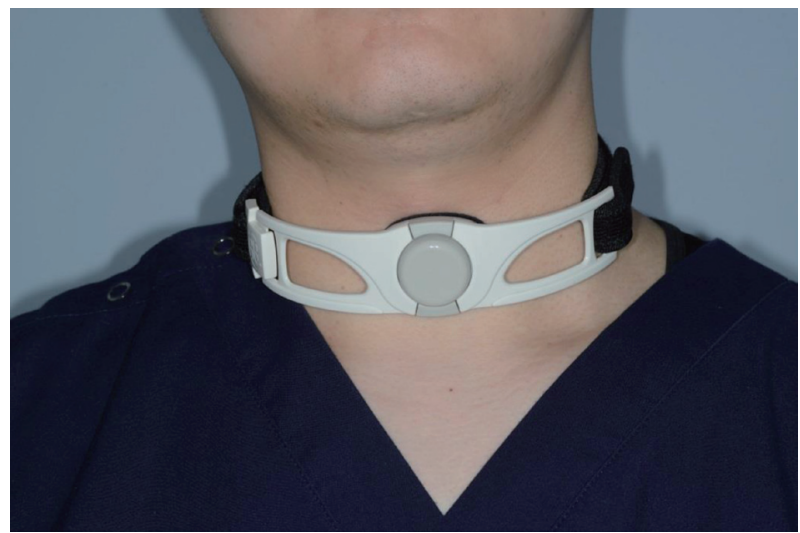

Fig. 2. The Reza band cushion is placed over the cricoid cartilage, which is right below the Adam's apple or laryngeal prominence. The Reza band is designed to apply a small amount of controlled external pressure to the upper esophageal sphincter area.
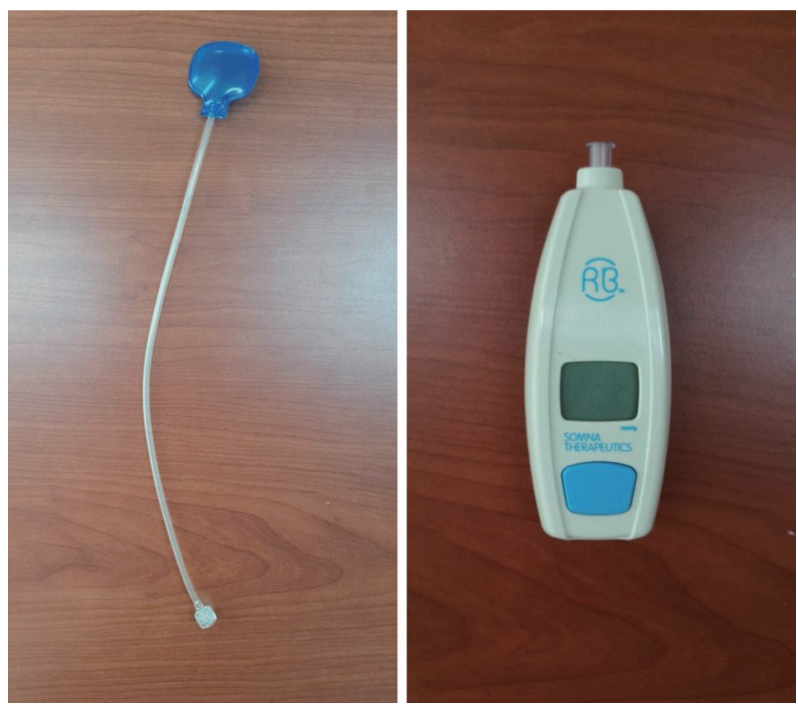

Fig. 3. The Reza band is fit for the patient using an external manometer along with a pressure sensor. This unit is designed to fit each patient to correct setting, which is $20-30 \mathrm{~mm} \mathrm{Hg}$. 
Reza band를 처방하고 착용 전과 착용 후 $2,4,8,12$ 주에 걸 쳐 외래로 방문하여 역류 증상 지수(Reflux Symptom Index, RSI)와 후두 역류 소견(Reflux Finding Score, RFS)을 측정 하고 Reza band 착용과 관련된 합병증을 조사하였다. RSI 는 환자 본인에 의해 작성된 설문지로 평가하였고 ${ }^{9)} \mathrm{RFS}$ 는 연 성 후두경으로 촬영된 영상을 한 명의 의사가 일괄적으로 평 가하였으며 ${ }^{10)}$ 또한 기도 폐색, 연하 곤란, 호흡 곤란, 인후두 출혈, 통증 등의 합병증 및 장치의 지속적 사용 여부를 확인 하였다. RSI는 13점, RFS는 7점 이상일 경우 인후두 역류 질 환 의심 환자로 진단하였으며 $24 \mathrm{hr} \mathrm{pH}$ monitoring 또는 24 hr intraluminal impedance 검사를 시행하지는 않았다. ${ }^{11}$

Reza band 치료 전후에 RSI 및 RFS의 변화를 비모수 검정 법인 Wilcoxon signed-rank test를 이용하여 비교하였으며, 통계학적 유의 수준은 $95 \%$ 이상 $(p<0.05)$ 으로 하였다.

\section{결 과}

총 16예 중 1예가 남성(6.3\%), 15예가 여성(93.7\%)이었으며 평

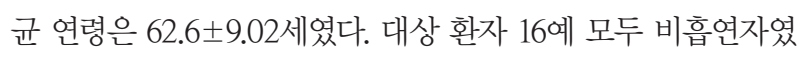
으며, 사회 통상적 음주력은 10예에서 있었으며 6예는 음주 력이 없었다. Body mass index(BMI)를 확인할 수 있었던 환 자는 16예 중 총 12예였으며 평균 $\mathrm{BMI}$ 는 $24.9 \pm 3.24$ 였다. Reza band를 착용하기 전 모든 환자들은 인후두 역류증으 로 PPI 약물치료 단독이나, PPI와 위장관 운동 촉진제의 병 합 약물치료를 받았으며, Reza band 착용 전 양성자 펌프 억 제제의 평균 치료 기간은 $12.7 \pm 23.8$ 개월이었다. 대상 환자들 은 Reza band와 PPI 치료를 같이하거나 Reza band만을 단 독으로 사용하였는데, Reza band와 PPI 병합치료가 14예, Reza band만을 단독 사용한 경우가 2예였다.

총 16명의 환자 중 Reza band 착용 후, 1 명(6.25\%)이 2주 뒤 외래 정기 내원 시 Reza band 착용 시 불편감만 있고 호전되 는 것 같지 않다고 하여 임의로 착용을 중지하였으며 나머지 15 명은 지속적으로 Reza band를 사용하였다. 중도 탈락한 환자 1 명을 제외한 15 명 중 12 주까지 모두 추적 관찰과 평가 가 가능하였던 환자는 10 명이었고 8 주 관찰한 환자가 3 명, 4 주 관찰한 환자가 2 명이었다. Reza band 착용 후의 합병증으로 는 착용 시 가벼운 목을 조르는 듯한 통증을 호소한 1명 외에 다른 특이 합병증은 없었다.

중도 탈락한 1 명을 제외한 15 명에서 $\mathrm{RSI}$ 는 착용 전보다 착 용 후 8주 $(p=0.005)$ 와 12주 $(p=0.007)$ 에 통계적으로 유의하 게 호전되었으며(Fig. 4), RFS는 착용 전에 비해 착용 후 2주 ( $p=0.011), 4$ 주 $(p=0.001), 8$ 주 $(p=0.002), 12$ 주 $(p=0.005)$ 에서 모두 통계적으로 유의하게 감소하였다(Fig. 5).

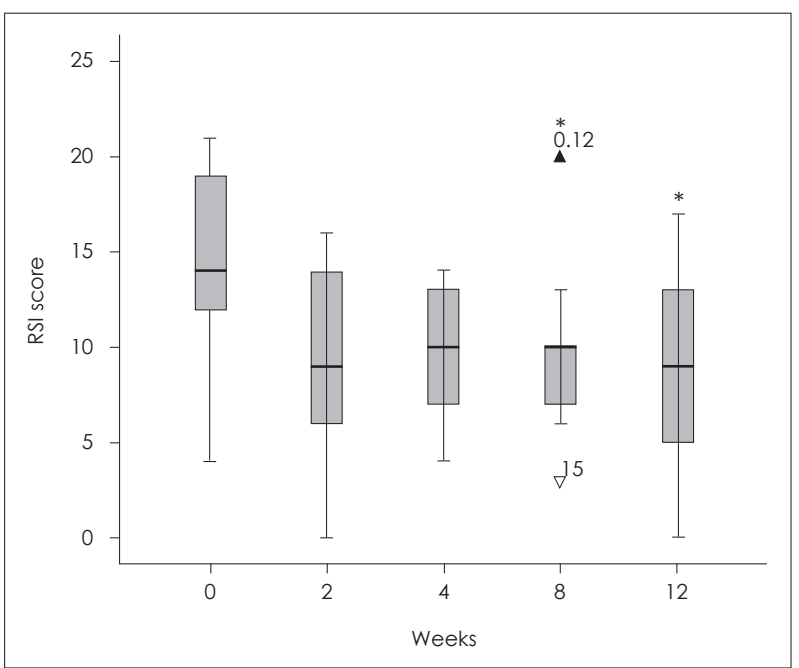

Fig. 4. Change of RSI in patients with laryngopharyngwal reflux disease who were treated with the Reza band. ${ }^{*} p<0.05$. RSI: Reflux Symptom Index.

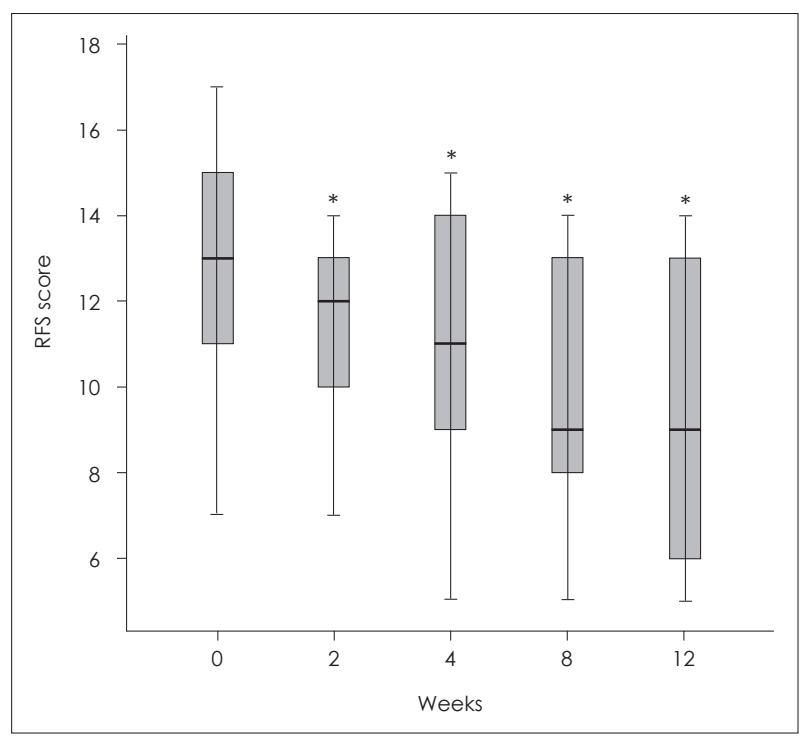

Fig. 5. Change of RFS in patients with laryngopharyngeal reflux disease who were treated with the Reza band. ${ }^{*} p<0.05$. RFS: Reflux Finding Scoe.

Reza band와 PPI를 동시에 사용한 군(13예)과 Reza band 만을 사용한 군(2예)으로 나누어 분석하였을 때는 Reza band 와 PPI 동시 사용 군에서는 통계적으로 유의하게 RSI 및 RFS 가 호전되었고(Table 1), Reza band만을 사용한 군(2예)에서 도 RSI 및 RFS가 착용 전보다 착용 후 호전되었으나 통계적 평가는 할 수 없었다.

\section{고 찰}

인후두 역류 질환의 치료는 이전에는 증상의 정도에 따라 단 계별로 생활습관의 개선 및 다양한 약물치료가 이루어졌으 
Table 1. Change of RSI and RFS in laryngopharyngeal reflux diseases patients who were treated with Reza band and proton pump inhibitor

\begin{tabular}{lcccc}
\hline & RSI & p value (vs. pre-treatment) & RFS & p value (vs. pre-treatment) \\
\hline 0 week & $12.46 \pm 6.05$ & & $13.85 \pm 2.61$ & $0.017^{*}$ \\
2 weeks & $10.27 \pm 8.66$ & 0.177 & $12.64 \pm 3.04$ & $0.003^{*}$ \\
4 weeks & $10.91 \pm 5.70$ & 0.172 & $11.09 \pm 2.88$ & $0.005^{*}$ \\
8 weeks & $8.00 \pm 4.11$ & $0.008^{*}$ & $10.60 \pm 2.76$ & $0.011^{*}$ \\
12 weeks & $7.38 \pm 5.88$ & $0.017^{*}$ & $9.25 \pm 2.96$ &
\end{tabular}

$* p<0.05$. RSI: Reflux Symptom Index, RFS: Reflux Findings Score

나 최근에는 양성자 펌프 억제제가 약물치료의 기본이다. ${ }^{12}$ 양성자 펌프 억제제를 3개월 정도 사용하였을 때 대부분 호 전되고 만약 치료에 반응이 없는 경우 용량을 두 배로 증량 하거나 치료 기간을 늘리는 것이 표준적인 치료로 정립되었 다. ${ }^{512-14)}$ 하지만 그럼에도 불구하고 양성자 펌프 억제제로 호 전되지 않는 인후두 역류 질환 환자가 있으며 또 장기간의 양성자 펌프 억제제 치료에 대한 불안감 및 거부감을 갖는 경우도 있다. 그런 경우 수술적 치료를 고려할 수도 있다. ${ }^{14}$

새로운 인후두 역류 질환의 치료법으로 상부식도 괄약근 보조 장치(UES assist device)가 고안되어 국외에서는 이미 사 용되고 있으며 이에 대한 연구가 진행되고 있다.8,15) $\mathrm{LPRD}$ 는 위식도의 역류물이 인후두로 올라오는 것을 방지하는 상부 식도 괄약근의 압력이 불충분하여 야기 되기 때문에 상부식 도 괄약근의 압력을 높이면 인후두 역류를 줄일 수 있다. El-Rifai 등 ${ }^{16}$ 은 LPR 증상이 있는 환자군의 91\%에서 상부식 도 괄약근이 이완되어 산이 역류된다 보고하였으며 Shaker 등 ${ }^{8}$ 은 상부식도 괄약근 보조 장치로 외부에서 윤상 연골에 20 30 mm Hg 의 압력이 가하면 인후두 역류를 방지할 수 있는 충분한 상부식도 괄약근 압력을 얻을 수 있다 하였다. Reza band는 상부식도 괄약근 부위를 눌러 인후두로 위 내 용물이 역류하는 것을 막아 LPRD의 증상을 호전시키며, 대 개 윤상 연골 위 위치에 위치시키고 적절한 압력을 가하며, 압력 측정기 및 압력 조절기가 따로 있어 적절한 압력을 조절 할 수 있다.

인후두 역류 질환의 증상을 일으키는 두 가지 기전이 있는 데, 하나는 상부식도 괄약근의 약화로 인한 직접적인 위산 역류로 인해 후두 및 인두가 자극되고 염증이 일어나며, 다른 하나는 미주 신경 반사 작용이 관련된다. ${ }^{17)}$ 미주 신경 반사 작 용 이론은 발생학적으로 식도와 기관지의 기원이 비슷하고 공통적으로 미주 신경이 분포하는데, 산의 역류가 일어날 때 원위 식도의 산성화가 산 민감성 수용체를 자극하여 식도 및 후두 자체의 증상 및 기침 등의 호흡기 증상도 일어난다는 것 이다. ${ }^{18)}$ 따라서 Reza band 같은 상부식도 괄약근 보조 장치 로 상부식도 괄약근의 압력이 높아지면 원위 식도의 산성화
가 감소하여 증상이 호전될 수 있다. Slivers 등의 연구에서 는 Reza band를 4주간 수면 시에 착용하게 하였으며 RSI가 Reza band 착용 후 2주부터 통계적으로 유의하게 32 61\% 정 도 호전되었고 LPRD에 의한 증상들인 가슴 쓰림(78\%), 삼킴 곤란(64\%), 식후 기침(63\%), 쉰 목소리(62\%) 등도 호전되었다 고 보고하였다. 부작용으로는 목 따가움, 쉰 목소리, 가벼운 피부 발진 및 약간의 목조름 느낌 정도였으며 심각한 부작용 이 보고된 바는 없다. ${ }^{7.8}$

본 연구는 PPI 치료에 충분한 효과가 없는 인후두 역류 질 환 의심 환자를 대상으로 인후두 역류 질환의 병태 생리의 근본적인 원인이라고 여겨지는 상부식도 괄약근의 압력을 높일 수 있는 상부식도 괄약근 보조 장치인 Reza band 적용 의 안정성과 예비 효과를 평가한 국내 첫 예비 연구라는 데 의의가 있다. Reza band의 사용에서 가장 큰 우려는 외부에서 직접적인 외력이 가해지는 만큼 통증 및 경부 압박에 의한 불 편감에 의한 사용 중단이었는데, 1 명을 제외한 약 $94 \%$ 의 환 자에서 Reza band 적용이 가능하였으며, 기구의 압력 조절 장 치로 적절한 압력점을 찾아내어 합병증을 최소화할 수 있었 다. 치료 효과 면에서도 Reza band 사용 후 통계적으로 유의 하게 RSI와 RSF가 호전되어 치료 효과가 있으리라 생각되 나, 많은 경우에서 Reza band와 동시에 PPI를 같이 사용하 여 Reza band 자체에 의한 효과만을 평가하기에 어려운 점 이 있고 Reza band를 사용하지 않는 대조군이 없는 연구라 는 제한점이 있어 이를 보완하기 위한 추가 연구가 필요하다 고 생각된다. 그러나 최소한 본 연구의 결과로 미루어 인후두 역류증 환자에서 Reza band의 사용은 중요 합병증이 없는 안전한 방법이라 생각되며, 예비 연구로 많은 제한점이 있지 만 향후 상부식도 괄약근 보조 장치를 활용한 치료 및 연구 에 기본 자료를 제공하리라 생각한다.

이 연구는 상부식도 괄약근 보조 장치인 Reza band에 관 한 국내 첫 예비연구로 인후두 역류 질환 환자에서 안전하게 적용할 수 있으며 양성자 펌프 억제제와 병합하여 사용하거 나 단독으로 적용할 수 있으리라 생각된다. 


\section{REFERENCES}

1) Schreiber S, Garten D, Sudhoff H. Pathophysiological mechanisms of extraesophageal reflux in otolaryngeal disorders. Eur Arch Otorhinolaryngol 2009;266(1):17-24.

2) Shin KS, Tae K, Jeong JH, Jeong SW, Kim KR, Park CW, et al. The role of psychological distress in laryngopharyngeal reflux patients: a prospective questionnaire study. Clin Otolaryngol 2010;35(1):25-30.

3) Szczesniak MM, Williams RB, Brake HM, Maclean JC, Cole IE, Cook IJ. Upregulation of the esophago-UES relaxation response: a possible pathophysiological mechanism in suspected reflux laryngitis. Neurogastroenterol Motil 2010;22(4):381-6, e89.

4) Szczesniak MM, Williams RB, Cook IJ. Mechanisms of esophagopharyngeal acid regurgitation in human subjects. PLoS One 2011; 6(7):e22630.

5) Lee YJ, Kwak MK, Eom JH, Ji YB, Song CM, Tae K. [Optimal regimen and period for the treatment of patients with laryngopharyngeal reflux disease]. Korean J Otorhinolaryngol-Head Neck Surg 2014; 57(10):698-702.

6) Tae K, Lee YS, Jeong JH, Park IB, Lee SH, Kim KR. The changes of reflux symptoms and laryngoscopic findings in treatment of patients with laryngopharyngeal reflux. J Korean Logo Phon 2005;16(1):15-8.

7) Slivers SL, Vaezi MF, Vakil NB, Raymond AR, Schmalz MJ, Higginbotham T, et al. Prospective study of upper esophageal sphincter assist device for treating extraesophageal reflux. Otolaryngol Open J 2016;2(1):31-8.

8) Shaker R, Babaei A, Naini SR. Prevention of esophagopharyngeal reflux by augmenting the upper esophageal sphincter pressure barrier. Laryngoscope 2014;124(10):2268-74.

9) Belafsky PC, Postma GN, Koufman JA. Validity and reliability of the reflux symptom index (RSI). J Voice 2002;16(2):274-7.

10) Belafsky PC, Postma GN, Koufman JA. The validity and reliability of the reflux finding score (RFS). Laryngoscope 2001;111(8):1313-7.

11) Oh JH, Ji YB, Song CM, Jung JH, Jin BJ, Tae K. Correlation between ambulatory 24 hour dual probe $\mathrm{pH}$ monitoring and reflux finding score, reflux symptom index in the laryngopharyngeal reflux. Korean J Otorhinolaryngol-Head Neck Surg 2013;56(11):706-10.

12) Berardi RR. A critical evaluation of proton pump inhibitors in the treatment of gastroesophageal reflux disease. Am J Manag Care 2000; 6(9 Suppl):S491-505.

13) Park W, Hicks DM, Khandwala F, Richter JE, Abelson TI, Milstein $\mathrm{C}$, et al. Laryngopharyngeal reflux: prospective cohort study evaluating optimal dose of proton-pump inhibitor therapy and pretherapy predictors of response. Laryngoscope 2005;115(7):1230-8.

14) Ford $\mathrm{CN}$. Evaluation and management of laryngopharyngeal reflux. JAMA 2005;294(12):1534-40.

15) Jiao H, Mei L, Liang C, Dai Y, Fu Z, Wu L, et al. Upper esophageal sphincter augmentation reduces pharyngeal reflux in nasogastric tube-fed patients. Laryngoscope 2017 Oct 8 [Epub ahead of print]. www.dx.doi.org/10.1002/lary.26895.

16) El-Rifai W, Szczesniak MM, Williams RB, Cook IJ. Mechanisms of esophago-pharyngeal acid regurgitation in human subjects. PLoS One 2011;6(7):e22630.

17) Groen JN, Smout AJ. Supra-oesophageal manifestations of gastrooesophageal reflux disease. Eur J Gastroenterol Hepatol 2003;15(12): 1339-50.

18) Rodríguez-Téllez M. Supra-oesophageal manifestations of gastrooesophageal reflux disease. Drugs 2005;65 Suppl 1:67-73. 